See Article page 1075 .

\section{Commentary: To remove (a heart), or not to remove, that is the question}

\author{
Kyle Hope, MD, ${ }^{\mathrm{a}}$ and Iki Adachi, $\mathrm{MD}^{\mathrm{b}}$
}

Because of the heterogeneity of pediatric heart failure, there are situations in which standard ventricular assist device (VAD) support is not sufficient, necessitating a more aggressive approach, such as total artificial heart (TAH) placement. Although commercially available TAHs, such as the SynCardia TAH (SynCardia Systems, LLC, Tucson, Ariz) are potential options for adolescents, such options do not exist for small children. Consequently, these patients are often supported with extracorporeal membrane oxygenation, despite its suboptimal outcomes and significant risk profile. In this context, the technique presented in this issue of the Journal by Woods and colleagues ${ }^{1}$ represents a unique and innovative option to enable TAH-like support in smaller children. The novelty of their approach is characterized by the use of the Berlin EXCOR cannulas (Berlin Heart Inc, The Woodlands, Tex) and associated cardiectomy, which makes the implant procedure more applicable even to conditions that may be unsuitable for typical VAD implantation, such as intracardiac tumor. Woods and colleagues ${ }^{1}$ are to be congratulated for the tenacity they have demonstrated, striving to save their patients in critical conditions.

One facet of this case series that certainly warrants further discussion is the patient population best served by the approach described by Woods and colleagues. ${ }^{1}$ A variety of pathologies were supported in this series. The proposed approach, however, should not supplant initial more conventional strategies, such as durable VAD support with

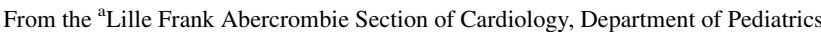
and ${ }^{b}$ Michael E. DeBakey Department of Surgery, Congenital Heart Surgery, Texas Children's Hospital, Baylor College of Medicine, Houston, Tex.

Disclosures: Dr Adachi serves as a consultant or proctor for Berlin Heart Inc, Medtronic Inc, Jarvik Inc, BiVACOR Inc, and Sony-Olympus Medical Solutions Inc. Dr Hope has nothing to disclose with regard to commercial support.

Received for publication Oct 23, 2019; revisions received Oct 23, 2019; accepted for publication Oct 23, 2019; available ahead of print Dec 12, 2019.

Address for reprints: Iki Adachi, MD, Michael E. DeBakey Department of Surgery, Congenital Heart Surgery, Texas Children's Hospital, Baylor College of Medicine, 6651 Main St, Houston, TX 77030 (E-mail: iadachi@bcm.edu).

J Thorac Cardiovasc Surg 2020;159:1083-4

$0022-5223 / \$ 36.00$

Copyright (C) 2019 by The American Association for Thoracic Surgery

https://doi.org/10.1016/j.jtcvs.2019.10.133
}

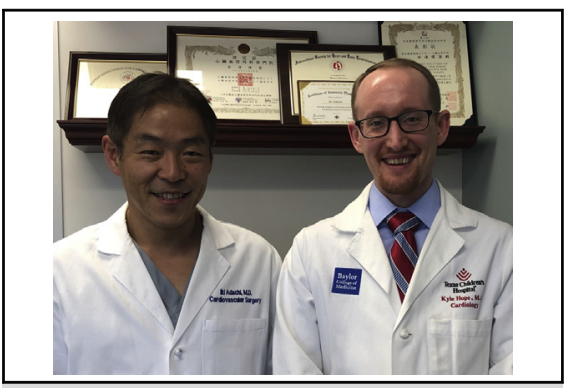

Iki Adachi, MD (left), and Kyle Hope, MD (right)

$$
\begin{aligned}
& \text { CENTRAL MESSAGE } \\
& \text { Pediatric biventricular failure } \\
& \text { represents a challenging clinical } \\
& \text { situation with limited options for } \\
& \text { support. Woods and colleagues } \\
& \text { describe innovative means of } \\
& \text { support for small infants and } \\
& \text { children. }
\end{aligned}
$$

medical support of the right ventricle. Rather, it ought to be considered as a last resort for patients with biventricular failure who could not otherwise be supported with conventional VAD alone. A VAD surgeon needs to be a minimalist, simply providing a support that is "just enough" and "not excessive."

One of the fundamental differences between VAD and TAH support is the presence or absence of a native cardiac chamber that serves as a reservoir for an artificial pump. Allowing a TAH to fill only partially may allow some capacity to accommodate abrupt increases in device preload. ${ }^{2}$ This can represent a double-edged sword, because accommodating variations in preload must be balanced against decreased stroke volume and cardiac output. Nevertheless, without proper reservoir capacity, excessively increased preload will result in direct transmission of higher pressures to the systemic and pulmonary venous systems. Woods and colleagues ${ }^{1}$ provide a thorough description of their strategies to minimize time spent in this state, which include the use of both upsized pumps and valved conduits. The fact that artificial pumps have robust systolic capabilities but limited diastolic reserve denotes the importance of retaining a cardiac chamber to accommodate changes in preload, whenever feasible. The optimal means of protecting the venous systems from high back pressure remains to be determined; 
however, careful consideration of the strategies put forth by Woods and colleagues ${ }^{1}$ in this article will be of utmost importance when considering this approach to cardiac support in future patients.

Pediatric heart failure in small children remains a challenge, with high mortality and limited options for mechanical support. The rescue strategy described by Woods and colleagues ${ }^{1}$ is a creative approach that could potentially save the lives of children in critical condition who would not be candidates for conventional VAD support. Further discussion is warranted to define the population best served by this aggressive approach.

\section{References}

1. Woods RK, Kindel S, Mitchell ME, Hraska V, Niebler RA. Evolving understanding of total artificial heart support of young infants and children. J Thorac Cardiovasc Surg. 2020;159:1075-82.

2. Copeland J, Arabia FA, Tenderich G, Marino A, Voigt O, Maiello C, et al. The total artificial heart. In: Montalto A, Loforte A, Musumeci F, Krabatsch T, Slaughter MS, eds. Mechanical Circulatory Support in End-Stage Heart Failure: A Practical Manual. Cham, Switzerland: Springer International Publishing; 2017: 313-36. 